\title{
Helping Babies Survive Training Programs: Evaluating a Teaching Cascade in Ethiopia
}

\author{
Weinberg Steven ${ }^{1}$, Jones Denise ${ }^{1}$, Worku Bogale ${ }^{2}$, Kumera Megerssa ${ }^{2}$, Bose \\ Carl $^{1}$, Patterson Jacquelyn ${ }^{1}$
}

\footnotetext{
OPEN ACCESS

Citation: Weinberg Steven, Jones Denise, Worku Bogale, Kumera Megerssa, Bose Carl, Patterson Jacquelyn. Helping Babies Survive Training Programs: Evaluating a Teaching Cascade in Ethiopia. Ethiop J Health Sci. 2019; 29(6):669.doi:http://dx.doi.org/10.4314/ej hs.v29 i 6.3

Received: May 22, 2019

Accepted: July 24, 2019

Published: November 1, 2019

Copyright: (C2019 Steven W, et al. This is an open access article distributed under the terms of the Creative Commons Attribution License, which permits unrestricted use, distribution, and reproduction in any medium, provided the original author and source are credited.

Funding: University of North Carolina School of Medicine Office of International Activities.

Competing Interests: The authors declare that this manuscript was approved by all authors in its form and that no competing interest exists.

Affiliation and Correspondence:

${ }^{1}$ Department of Pediatrics at the

University of North Carolina School of

Medicine.

${ }^{2}$ Ethiopian Pediatric Society.

Email:

steven.weinberg@unchealth.unc.edu
}

\section{ABSTRACT}

Background: 2.6 million neonates die annually; the vast majority of deaths occur in low- and middle-income countries (LMICs). The Helping Babies Survive (HBS) programs are commonly used in LMICs to reduce neonatal mortality through education. They are typically disseminated using a train-the-trainer cascade. However, there is little published literature on the extent and cost of dissemination. In 2015, the Ethiopian Ministry of Health and partner organizations implemented a countrywide HBS training cascade for midwives in 169 hospitals.

Methods: We quantified the extent of HBS dissemination, and characterized barriers that impeded successful hospital-based training by surveying a representative from each of the 169 participant hospitals. This occurred from September 2017 to April 2018. We also assessed the cost of the training cascade. To assess acquisition of knowledge and skill in the training cascade, multiple-choice question examinations (MCQE) and objective structured clinical evaluations (OSCE) were conducted.

Results: Hospital-based training occurred in 132 participant hospitals (78\%). 1,146 midwives, 69\% of those employed by participant hospitals, received hospital-based training. Barriers included lack of preparation of hospital-based educators and limited logistical support. The cascade cost an average of 2,105 USD per facility or 197 USD per trainee. Knowledge improved and skills were adequate for regional workshop attendees based on $M C Q E$ and $O S C E$ performance.

Conclusion: The train-the-trainer strategy is an effective and affordable strategy for widespread dissemination of the $H B S$ programs in LMICs. Future studies should assess knowledge and skill acquisition following the variety of pragmatic training approaches that may be employed at the facility-level.

Keywords: Global Health, Education, Infant, Newborn, Helping Babies Survive, Helping Babies Breathe, Training

\section{INTRODUCTION}

Each year, approximately 2.6 million neonates die (1). The vast majority of these deaths occur in low- and middle-income countries(LMICs) (2). It is estimated that $50 \%$ of these deaths are 
preventable with low-cost, evidence-based practices $(2,3)$. However, a lack of knowledge and skills regarding these practices is a barrier to widespread implementation. Thus, educating health providers is a widely recognized, necessary step in reducing neonatal mortality. The Helping Babies Survive (HBS) programs developed by the American Academy of Pediatrics are commonly used in LMICs to educate providers in evidence-based care. HBS consists of three modules: Helping Babies Breathe (HBB) trains birth attendants in basic resuscitation; Essential Care for Every Baby (ECEB) teaches providers newborn care practices from the time of birth to discharge home; Essential Care for Small Babies (ECSB) trains providers in specialized care required for small and preterm babies (4-6). The HBS programs rely on low-cost materials and a lowtechnology platform that includes visual aids to illustrate teaching points, pictorial action plans that guide clinical practice, and simulation cases with low-fidelity manikins. To date, HBB has been taught in over 80 countries and the entire HBS suite in over 20 countries (7). Evaluations of the educational effectiveness of the HBS programs consistently demonstrate increased knowledge and skills following training (8-13). There is also evidence that implementation of HBB reduces perinatal mortality (14-16).

HBS programs are typically disseminated using a train-the-trainer cascade in which a cohort of master trainers are trained, and then tasked with training others. The cascade may include multiple levels of trainings, culminating in peer-to-peer education at the individual hospital level. This trainthe-trainer cascade model is particularly suitable for LMICs as it is an economical strategy for scale-up. However, there is little published literature on the extent and nature of dissemination that takes place at the hospital level, or the cost of implementing such training cascades.

Beginning in 2015, the Ethiopian Ministry of Health $(\mathrm{EMoH})$, in partnership with the Ethiopian Pediatric Society (EPS) and the Survive and Thrive Global Development Alliance (S\&T GDA), implemented a countrywide HBS training cascade for hospitals across Ethiopia. Their goal was to train all midwives, often the exclusive providers of newborn care, in these hospitals. The purpose of this report is to quantify the extent of HBS dissemination, characterize the train-the-trainer cascade to highlight barriers that impede successful dissemination, and assess the cost of this training.

\section{MATERIALS AND METHODS}

Setting and participants: In 2004, the $\mathrm{EMoH}$ began its Health Expansion Programme. This program resulted in an increase in the percent of live births attended by skilled health personnel $(17,18)$. Despite this increased access to care, in 2014 the neonatal mortality rate in Ethiopia remained high at 31/1,000 live births (19). This rate prompted the inclusion of Ethiopia as a priority country for the S\&T GDA Helping 100,000 Babies Survive and Thrive initiative (20). The EMoH, in partnership with the EPS, identified a lack of knowledge and skill among newborn care providers as a gap in quality, and contributor to neonatal mortality. With funds from this initiative, they developed a plan to close this gap through an HBS training cascade for midwives in every hospital in the country.

In September 2015, six experienced HBS trainers from the United States, Ethiopia, and Uganda prepared 16 Ethiopian pediatricians as HBS Master Trainers during a four-day course. An additional 17 were trained in June 2016. With logistical support provided by the EPS, from July to October 2016 at seven sites around the country these master trainers conducted 21 regional HBS training workshops for representatives from 169 participating hospitals. Four representatives from each participating hospital were invited to attend one of the regional workshops. At that time, there were 180 hospitals in the country. Nine hospitals from the Somali, Dire Dawa, and Harari regions were excluded secondary to unsafe conditions for travel to these regions and two hospitals in the Addis Ababa region chose not to participate (Table 1). The regional workshops lasted three days and ranged in size from 21 to 40 participants, with one master trainer for every six to eight trainees. HBB was taught during the first day with ECEB and ECSB taught during the second two days. In total, 662 providers were trained at these regional workshops. Over $95 \%$ of trainees were midwives; the other $5 \%$ were nurses or house officers.

DOI: http://dx.doi.org/10.4314/ejhs.v29i6.3 
Table 1. Regional HBS training workshop participation by region.

\begin{tabular}{llll}
\hline Region & $\begin{array}{l}\text { Participating } \\
\text { Hospitals }\end{array}$ & $\begin{array}{l}\text { Excluded } \\
\text { Hospitals }\end{array}$ & Regional Workshop Attendees \\
\hline Oromia & 38 & & 152 \\
Amhara & 52 & & 218 \\
SNNPR* & 43 & & 164 \\
Tigray & 22 & & 75 \\
Afar & 3 & 7 & 13 \\
Somali & 0 & 2 & 0 \\
Addis Ababa & 8 & & 29 \\
Gambela & 1 & & 3 \\
Benshangul & 1 & 1 & 4 \\
Dire dawa & 1 & 1 & 4 \\
Harari & 0 & 11 & 0 \\
Total & 169 & 662 \\
\hline
\end{tabular}

Note: *Southern Nations, Nationalities, and People's Region

At the regional workshops, each hospital received a set of HBS teaching tools and participants were instructed in how to utilize these resources. After the regional workshops, attendees were expected to return to their sponsoring hospitals and share what they learned with other midwives. A schedule and strategy for doing so was not advised, a lead person from each health facility was not identified, and funding for this final phase of dissemination was not provided.

Data describing hospital-based training:We collected data describing training at each hospital using a scripted survey tool that we designed specifically for this study. It included both closed and free-response questions. Respondents selfdefined whether they trained their peers. From September 2017 to April 2018, an EPS employee used this tool to survey a regional workshop attendee from each of the 169 hospitals in Amharic, either in person or over the phone based on geographic accessibility. The EPS employee utilized previously collected phone numbers to contact regional workshop attendees, explained that participation was voluntary, and administered the survey to the first regional workshop attendee from each hospital who was available to participate and answer the survey's questions.

Both those who did and did not train peers were asked about expectations, instruction, and preparedness for hospital-based training.
Additionally, those who trained others were asked about number and professional category of trainees, and methods used for training. We analyzed free-response descriptions of how training was conducted for themes, and ultimately categorized training as happening during a preestablished weekly meeting or lunch meeting, during clinical care, or outside of work hours. Those who did not train their peers were asked about barriers that impeded successful hospitalbased dissemination of HBS. We analyzed freeresponse descriptions of barriers encountered for themes, and ultimately categorized barriers as a lack of time, budget, or ability to provide refreshments. Qualtrics online software was utilized for the EPS employee to record the data gathered. Data were then exported to Microsoft Excel for analysis.

Data describing cost of training: To inform stakeholders about the cost of implementation of the HBS programs using the train-the-trainer strategy, we collected data describing the costs associated with the initiative in Ethiopia. Costs included expenses incurred for activities in the cascade after the master trainers had been prepared. We categorized costs into: 1) equipment and supplies, 2) costs incurred at regional workshops, and 3) administrative overhead. We could not quantify the cost of hospital-based training.

DOI: http://dx.doi.org/10.4314/ejhs.v29i6.3 
Data describing acquisition of knowledge and skills: To assess knowledge attained during training, we administered a 17-question multiplechoice question examination (MCQE) before and after HBB training for regional workshop attendees. We used the MCQE that accompanies the HBB training program as our evaluative tool. Similar to prior HBB education evaluations, trainees were expected to answer 14 out of 17 questions (greater than 80\%) correctly to pass the MCQE (21). To assess skills at the completion of training, we recorded the results of one of the objective structured clinical evaluations (OSCE B) that accompanies the HBB program. Completion of 14 of the 18 tasks was considered a passing score. Because the duration of training was limited to three days, time did not allow for an assessment of ECEB and ECSB knowledge and skills using the MCQEs and OSCEs that accompany those programs. We did not collect data on acquisition of knowledge and skills for hospital-based training.

Role of institutional review board and funding source: Given the nature of the study, institutional review board approval was deemed unnecessary. Individuals included in the study participated voluntarily. The funding from the S\&T GDA International Trainers $(n=6)$
Helping 100,000 Babies Survive and Thrive initiative that enabled the HBS training cascade in Ethiopia did not support the efforts of this study. The only funding for this study was from the University of North Carolina School of Medicine Office of International Activities to support the lead author's travel to Ethiopia for data collection.

\section{RESULTS}

Number of providers trained: Hospital-based training occurred in 132 of the 169 included hospitals (78\%), with 1,146 midwives receiving hospital-based training. Among the 37 hospitals $(22 \%)$ in which no hospital-based training occurred, six reported that all of their midwives attended the regional workshops or another formal HBS training so further hospital-based training was not necessary. Therefore, no hospital-based training occurred in 31 hospitals (18\%) in which it was expected. Including providers trained at the regional workshops and thereafter, a total of 1,808 providers were trained (Figure 1). This represents $69 \%$ of all midwives employed by participant hospitals at the time our survey was conducted.

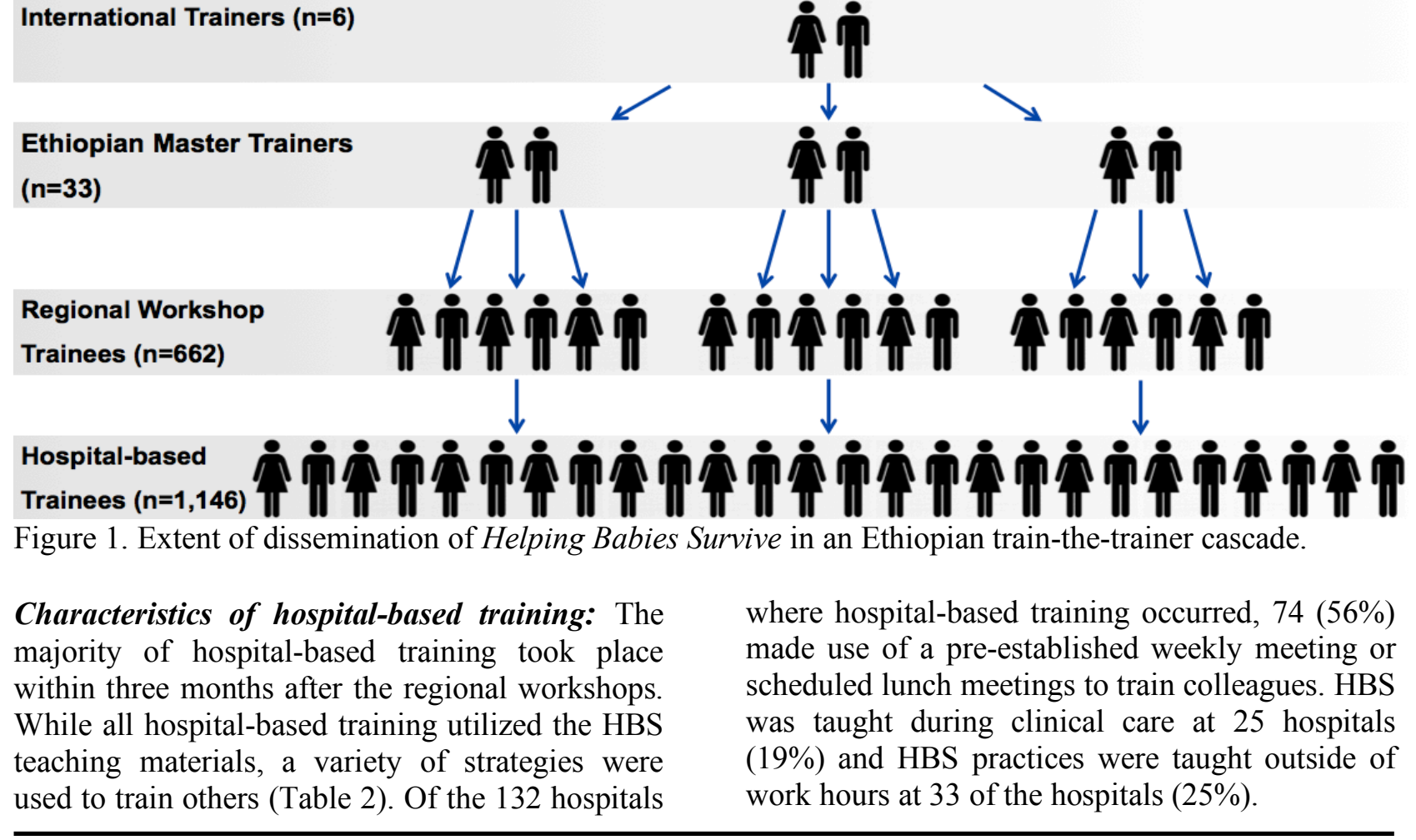

DOI: http://dx.doi.org/10.4314/ejhs.v29i6.3 
Table 2. Setting for and barriers to hospital-based training

\begin{tabular}{ll}
\hline Setting for hospital-based training & \\
\hline $\begin{array}{l}\text { Category } \\
\text { During pre-established weekly meeting or lunch }\end{array}$ & $\begin{array}{l}\text { Number of hospitals who completed training (\%) } \\
\text { meeting }\end{array}$ \\
$\begin{array}{ll}\text { During clinical care } \\
\text { During a training scheduled outside of work hours }\end{array}$ & $25(19 \%)$ \\
& \\
Barriers to hospital-based training & Number of hospitals who did not complete \\
Category & training (\%*) \\
Did not understand expectation to train others & $2(6 \%)$ \\
Limited time & $23(74 \%)$ \\
Limited budget & $23(74 \%)$ \\
Unable to provide tea or coffee & $13(42 \%)$ \\
\hline
\end{tabular}
Note: ${ }^{*}$ Total not equal to $100 \%$; multiple barriers reported by some hospitals.

Barriers to hospital-based training: In the 31 hospitals in which no hospital-based training occurred but was expected, those surveyed uniformly expressed confidence in their ability to provide care consistent with HBS guidelines. Nearly all confirmed their understanding of the expectation that they would return to their hospitals to teach HBS to others (94\%). However, they reported local barriers in fulfilling this obligation (Table 2). Respondents often reported that their ability to train others was limited by available time (74\%) and that a budget for hospital-based training would have allowed them to teach HBS more thoroughly or to more providers $(74 \%)$. Providing tea or coffee was often cited specifically as a potential way to increase participation in hospital-based training (42\%). Additional local barriers included lack of department logistical support, high employee turnover rates, and the requirement for providers to cover many service areas (e.g., triage, emergency department) interfering with efforts to concentrate educational training sessions. Some reported that a letter of support from the EPS to administrators explaining the importance of HBS training could have made arranging a training session easier. Respondents also indicated that additional training in how to teach the programs to others would have been helpful.
Cost of training: Educational equipment and supplies for the entire training cascade were donated by Laerdal Global Health. This donation was valued at 87,461 USD and included the cost of equipment (ventilation bag and masks, suction devices, NeoNatalie and MamaBreast manikins and kangaroo mother care garments), teaching supplies (flip charts, provider guides and action plan posters) and shipping. The cost of the regional workshops was 250,800 USD. This included honoraria for master trainers who led regional workshops, facility rental, meals and refreshments, and per diem and travel expenses for master trainers and trainees at regional workshops. The EPS administered the regional workshops at a cost of 17,556 USD (7\% of the direct costs of the regional workshops). We were unable to quantify the cost of hospital-based training beyond the cost of equipment and supplies. However, from the descriptions of hospital-based training gathered through surveys, we estimate that these additional costs were negligible. Thus, we estimate that the total costs for this training cascade was 355,817 USD. This equates to an average of 2,105 USD per facility and 197 USD per trainee for the 1,808 providers trained in the cascade.

Acquisition of knowledge and skills: Results of pre- and post-training MCQE and post-training OSCE scores were available for $361(55 \%)$ and $389(59 \%)$ of regional work shop trainees,

DOI: http://dx.doi.org/10.4314/ejhs.v29i6.3 
respectively. The mean pre-training score on the HBB MCQE was $76 \pm 18 \%$ with a passing rate of $51 \%$. The scores significantly improved $(\mathrm{p}<0.001)$ to a mean of $89 \pm 11 \%$ after training, with a passing rate of $84 \%$. Among the trainees who completed the HBB OSCE B, 362 (93\%) achieved a passing score.

\section{DISCUSSION}

The EMoH in partnership with the EPS established the goal of increasing the knowledge and skill of newborn care providers in Ethiopian hospitals in an effort to reduce neonatal mortality. In this manuscript, we describe the use of a trainthe-trainer model to disseminate the HBS teaching programs. Because nearly all newborn care immediately after birth is provided by midwives, the focus of this strategy was educating midwives. Through a cascade of preparing master trainers, regional workshops and hospital-based training, nearly $70 \%$ of midwives at 169 of the country's 180 hospitals received training in HBS.

We identified several potentially modifiable barriers to hospital-based training through surveys of regional workshop attendees who did not train colleagues upon returning to their hospital. These included lack of specific preparation for regional workshop attendees to fulfill their role as hospitalbased educators. Implementers of a train-thetrainer strategy should build this preparation into the curriculum. Of the hospital representatives who attended the regional workshops, a lead person in charge of hospital-based training at each facility was not identified. Designating a leader from each hospital could increase hospital-based training. Survey respondents also identified a lack of time allocated for hospital-based training and lack of support of trainers and trainees as barriers. Communication from the implementing organization, or ministry of health, directly to hospital administrators underlining the importance of their support may help remove some of these barriers. To ensure success of hospital-based training, administrators and clinical leaders should commit to local support before regional training and fulfill these commitments thereafter. This support might include the provision of refreshments during hospital-based training, defining supervision of training as a designated task for facilitators, and identifying a time and space for training. Finally, the need for providers to cover multiple clinical services competes with training opportunities, and high turnover rates of newborn providers increases the demand for training. These barriers may not be easily modified.

We analyzed the cost of disseminating the HBS programs to assist health care planners contemplating the use of these programs. The approximate cost to train each provider was 200 USD. This estimate did not include the cost of preparing Ethiopian Master Trainers, or the cost of hospital-based training beyond that of equipment and supplies (though we estimate that these additional costs were negligible). The cost of implementing HBS programs through a train-thetrainer cascade will be greater if master trainers are not locally available at the initiation of the cascade. Our reported cost compares favorably to the cost per trainee estimated by Chaudhury et al. (157 USD) in their analysis of a large-scale implementation of the HBB program in Tanzania, as that cost was for the training of providers in only one of the three HBS programs (22). However, their implementation strategy included more intense surveillance after the initial training. This addition to the typical train-the-trainer model added cost, but may facilitate the translation of education into clinical practice.

Our data suggest that knowledge regarding resuscitation improved as a result of HBB training, and skills were adequate among trainees in the regional workshops. However, there were two substantive limitations in our method of evaluating knowledge and skill acquisition. We did not have results of exams and OSCEs for all attendees at the regional workshops, and the results were from a non-random sample. Therefore, there is a risk of reporting bias. However, we are reasonably confident that the results among trainees tested was representative of all trainees because similar improvements in knowledge and skills have been demonstrated previously following HBB training (8-10). Further, although we did not perform preand post-tests and OSCEs with ECEB and ECSB training, we presume that trainees also gained knowledge and acquired skills as a result of ECEB and ECSB training because these benefits have

DOI: http://dx.doi.org/10.4314/ejhs.v29i6.3 
been reported previously for all three of the HBS programs $(8-10,12,13)$. Therefore, we can be reasonably confident about the improvement in knowledge and skills required to provide newborn care during the regional workshops. However, we do not know the extent to which the fidelity of the training was preserved during hospital-based training. Additionally, we are uncertain about the relative quality of the various training strategies used at the hospital-based level in this cascade, and thus cannot draw conclusions about improvements in knowledge and skill following training at the hospital level. Future studies should assess acquisition of knowledge and skill following a variety of pragmatic training strategies that may be commonly employed at the facilitylevel of a training cascade. Most importantly, we do not know whether processes of care improved, with resultant improvement in newborn outcomes, as a result of training. Recognizing that education is only an enabling step in improving outcomes, training programs should be combined with strategies to monitor and improve the quality of care.

A limitation of our study design was the potential role that social desirability bias could have played in responses we received from participants. Although we were not surveying them about sensitive or stigmatized behavior, there was an expectation that attendees of regional workshops would return to their hospitals and train others. This expectation could have affected participant's perception of "normative" behavior and prompted them to over-report training when surveyed. We attempted to minimize this bias through an introduction that framed the survey in light of the EPS wanting to understand how they could make training others easier. Additionally, the survey was administered in Amharic by an Ethiopian nurse of similar training to those surveyed. Although social desirability bias may have affected the accuracy of our reported numbers trained at the hospital level, we believe the estimate reported in this manuscript is valuable to program implementers of the HBS suite given the lack of published data on final stages of a training cascade performed outside of a research context. Furthermore, social desirability bias is less likely to have impacted the data we report in this manuscript regarding characteristics of hospital-based training and barriers to training. The data we report on the cost of training and acquisition of knowledge and skills are not subject to social desirability bias.

For the HBS programs there is little published literature on dissemination at the hospital level in train-the-trainer cascades and the cost of such trainings. We aim for this study to assist stakeholders contemplating the use of HBS programs as it quantifies the extent of HBS dissemination, characterizes barriers that impeded successful dissemination, and assesses the cost of a train-the-trainer cascade in a countrywide roll out of HBS in Ethiopia.

\section{AKNOWLEDGMENTS}

\section{REFERENCES}

1. Neonatal Mortality. Available from: https://data.unicef.org/topic/childsurvival/neonatal-mortality/. Accessed October 182017.

2. Bhutta ZA, Black RE. Global maternal, newborn, and child health--so near and yet so far. N Engl J Med. Dec 5 2013;369(23):22262235.

3. Lawn JE, Wilczynska-Ketende K, Cousens $\mathrm{SN}$. Estimating the causes of 4 million neonatal deaths in the year 2000. Int $J$ Epidemiol. Jun 2006;35(3):706-718.

4. Helping Babies Breathe. Available from: https://www.aap.org/en-us/advocacy-andpolicy/aap-health-initiatives/helping-babiessurvive/Pages/Helping-Babies-Breathe.aspx. Accessed September 192017.

5. Essential Care for Every Baby. Available from: https://www.aap.org/en-us/advocacyand-policy/aap-health-initiatives/helpingbabies-survive/Pages/Essential-Care-EveryBaby.aspx. Accessed September 192017.

6. Essential Care for Small Babies. Available from: https://www.aap.org/en-us/advocacyand-policy/aap-health-initiatives/helping- 
babies-survive/Pages/Essential-Care-SmallBabies.aspx. Accessed September 192017.

7. Our Global Presence. Helping Babies Survive. Available from: https://www.aap.org/en-us/advocacy-andpolicy/aap-health-initiatives/helping-babiessurvive/Pages/Our-Global-Presence.aspx. Accessed September 192017.

8. Singhal N, Lockyer J, Fidler H, et al. Helping Babies Breathe: global neonatal resuscitation program development and formative educational evaluation. Resuscitation. Jan 2012;83(1):90-96.

9. Hoban R, Bucher S, Neuman I, Chen M, Tesfaye N, Spector JM. 'Helping babies breathe' training in sub-saharan Africa: educational impact and learner impressions. $J$ Trop Pediatr. Jun 2013;59(3):180-186.

10. Seto TL, Tabangin ME, Josyula S, Taylor KK, Vasquez JC, Kamath-Rayne BD. Educational outcomes of Helping Babies Breathe training at a community hospital in Honduras. Perspect Med Educ. Oct 2015;4(5):225-232.

11. Arlington L, Kairuki AK, Isangula KG, et al. Implementation of "Helping Babies Breathe": A 3-Year Experience in Tanzania. Pediatrics. May 2017;139(5).

12. Thukral A, Lockyer J, Bucher SL, et al. Evaluation of an educational program for essential newborn care in resource-limited settings: Essential Care for Every Baby. BMC Pediatr. Jun 24 2015;15:71.

13. Berkelhamer S, Bose $\mathrm{C}$, Bucher $\mathrm{S}$, et al. Essential Care for Small Babies Improves Knowledge, Performance and Confidence in Caring for Small Babies. Poster presentation presented at: Pediatric Academic Societies 2017 Meeting; May 6-9, 2017; San Francisco, CA. Available from: http://cdn.laerdal.com/downloads/f3586/ECS B_FINAL.pdf. Accessed October 18, 2018.

14. Mduma E, Ersdal H, Svensen E, Kidanto H, Auestad B, Perlman J. Frequent brief on-site simulation training and reduction in 24-h neonatal mortality--an educational intervention study. Resuscitation. Aug 2015;93:1-7.

15. Msemo G, Massawe A, Mmbando D, et al. Newborn mortality and fresh stillbirth rates in Tanzania after helping babies breathe training. Pediatrics. Feb 2013;131(2):e353360.

16. Dol J, Campbell-Yeo M, Murphy GT, Aston M, McMillan D, Richardson B. The impact of the Helping Babies Survive program on neonatal outcomes and health provider skills: a systematic review. JBI Database System Rev Implement Rep. Mar 2018;16(3):701737.

17. Ethiopia's human resources for health programme. 2008; Available from: http://www.who.int/workforcealliance/knowl edge/resources/casestudy_education_ethiopia /en/. Accessed September 192017.

18. Countdown to 2015 maternal, newborn, \& child survival. Ethiopia country profile. 2013; Available from: http://www.who.int/gho/countries/eth/country profiles/en/. Accessed September 192017.

19. World Health Statistics data visualizations dashboard | Data table - Country data. Available from: http://apps.who.int/gho/data/node.sdg.3-2data?lang=en. Accessed May 202018.

20. Survive \& Thrive. Available from: https://surviveandthrive.org/Pages/default.asp x. Accessed October 182018.

21. Bang A, Patel A, Bellad R, et al. Helping Babies Breathe (HBB) training: What happens to knowledge and skills over time? BMC pregnancy and childbirth. Nov 22 2016;16(1):364.

22. Chaudhury S, Arlington L, Brenan S, et al. Cost analysis of large-scale implementation of the 'Helping Babies Breathe' newborn resuscitation-training program in Tanzania. BMC Health Serv Res. Dec 1 2016;16(1):681. 